Research paper

\title{
A thermoelectric generator using loop heat pipe and design match for maximum-power generation
}

\author{
Bin-Juine Huang a, *, Po-Chien Hsu a, Rung-Je Tsai a , Muhammad Mustafa Hussain ${ }^{b}$ \\ a Department of Mechanical Engineering, National Taiwan University, Taipei, 106, Taiwan \\ ${ }^{\mathrm{b}}$ Electrical Engineering Program, Physical Science and Engineering Division, King Abdullah University of Science and Technology (KAUST), Saudi Arabia
}

\section{H I G H L I G H T S}

- We develop thermoelectric generator (TEG) using loop heat pipe and design for maximum power.

- TEG uses loop heat pipe to dissipate heat without consuming power and free of noise.

- TEG using design match for maximum-power generation performs better than TEG with MPPT.

\section{A R T I C L E I N F O}

\section{Article history:}

Received 30 April 2015

Accepted 18 August 2015

Available online 5 September 2015

\section{Keywords:}

Thermoelectric generator

Thermoelectricity

Thermoelectric energy

Waste heat utilization

\begin{abstract}
A B S T R A C T
The present study focuses on the thermoelectric generator (TEG) using loop heat pipe (LHP) and design match for maximum-power generation. The TEG uses loop heat pipe, a passive cooling device, to dissipate heat without consuming power and free of noise. The experiments for a TEG with $4 \mathrm{~W}$ rated power show that the LHP performs very well with overall thermal resistance $0.35 \mathrm{~K} \mathrm{~W}^{-1}$, from the cold side of TEG module to the ambient. The LHP is able to dissipate heat up to $110 \mathrm{~W}$ and is maintenance free. The TEG design match for maximum-power generation, called "near maximum-power point operation (nMPPO)", is studied to eliminate the MPPT (maximum-power point tracking controller). nMPPO is simply a system design which properly matches the output voltage of TEG with the battery. It is experimentally shown that TEG using design match for maximum-power generation (nMPPO) performs better than TEG with MPPT.
\end{abstract}

() 2015 Elsevier Ltd. All rights reserved.

\section{Introduction}

Waste heat can be used to generate electricity using thermoelectric generator (TEG). TEG utilizes the thermoelectric effect to generate electric power from a temperature difference across the device. The new material of TEG has been extensively studied in recent years. Advanced TEG material with electric conversion efficiency higher than $10 \%$ has been published, for example, El-Genk and Saber [1]. The thermoelectric generator module commercially available in the market can generate electric power at conversion efficiency about $8 \%$ and the cost is reduced quickly. This will make the TEG technology be adopted in various applications such as waste heat recovery, independent power system such as small heat-driven battery charger etc.

\footnotetext{
* Corresponding author. Tel.: +886 918291621; fax: +886 223640549

E-mail address: bjhuang@seed.net.tw (B.-J. Huang).
}

Many researchers [2-4] developed TEG products to charge batteries of electronic equipment. They use a DC/DC converter (charger) to boost-up the TEG output voltage to charge the battery. The TEG power generation is not optimized and may be very low.

It is known that the output current of thermoelectric generator decreases linearly with increasing voltage at fixed hot and cold side temperature, $T_{h}$ and $T_{c}$. And, for a fixed $T_{h}$ and $T_{c}$, there exists an optimum power output (maximum-power point, MPP) at certain output voltage. A MPP tracking control (MPPT) is thus needed to control the TEG to operate at the maximum power all the time at varying operating conditions [5,6]. This is similar to the MPPT of solar PV module.

The MPPT of a TEG is usually designed using switching power electronics circuit, a DC/DC converter. For a stand-alone TEG system, a battery is included to store the electrical energy generated, as shown in Fig. 1. Similar to solar PV module, the MPPT can be used to regulate the output of TEG $\left(V_{T E G}\right)$ at $V_{M P P}$ which varies with the operating conditions $\left(T_{h}\right.$ and $\left.T_{c}\right)$. However, the circuit of MPPT will 


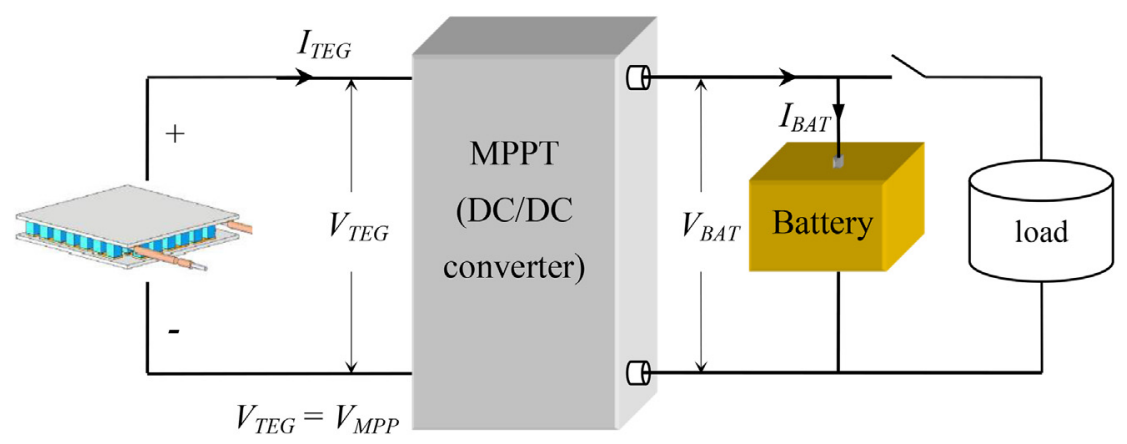

Fig. 1. Schematic diagram of TEG with MPPT.

cause some system response effect between its input and output and has energy loss.

Eakburanawat and Boonyaroonate [5] developed a thermoelectric battery charger with microcontroller-based maximumpower point tracking controller to obtain the maximum power output of TEG. The MPPT uses a SEPIC (single-ended primary inductance converter) DC/DC converter controlled by a microcontroller. SEPIC is a non-inverting DC/DC converter with output voltage either above or below the input. A TEG module with $5.9 \mathrm{~W}$ rated output power was designed and tested [5]. The battery charge current is directly controlled by the duty cycle of the PWM (pulsewidth-modulation) signal applied to the DC/DC converter to obtain the optimal power charge to the battery. The method of perturbation and observation (P.O. method) used in MPPT of photovoltaic (PV) module [7] was adopted to achieve the maximum power output by increasing or decreasing the value of the duty cycle according to the direction of consequent power change. The proposed TEG system has a maximum charging power of $7.99 \mathrm{~W}$ that is better than charging without MPPT by about $15 \%$. The MPPT of TEG described above [5] can maximize the power output all the time. However, MPPT is made from power electronics circuit which has energy loss and reliability problem due to failure of the circuit.

In addition to the MPPT problem, the current commercial thermoelectric module generates power at relatively low efficiency $(<8 \%)$. The majority of heat input to TEG should be dissipated. Conventional heat sink device using fins with fans will consume about $2-3 \mathrm{~W}$ for dissipating $100 \mathrm{~W}$ heat to the ambient. Hence, the net power generation of TEG system will be greatly reduced, especially for a small battery charger.

In the present study, we focuses on TEG using loop heat pipe and design match for maximum-power generation to eliminate the MPPT. The loop heat pipe (LHP), a passive cooling device, is used to dissipate the heat to the ambient by free convection. A so-called "near maximum-power point operation (nMPPO)" for TEG design is developed in order to avoid the MPPT. nMPPO design is simply a system design match which properly matches the output voltage of
TEG with the battery (Fig. 2). The design concept of nMPPO is feasible if the reduction of nMPPO power generation from the MPP is less than the energy loss of the MPPT circuit. The concept of nMPPO has been successfully used in solar PV system design [8].

\section{Design of TEG using loop heat pipe}

\subsection{Design of TEG system SYS-1}

The commercial TEG module used in the present study can generate electric power at about $4 \%$ conversion efficiency. $96 \mathrm{~W}$ heat should be dissipated for a $4 \mathrm{~W}$ power output. Conventional heat sink using fins and fans will consume about $2-3 \mathrm{~W}$. The net power output is very little. We utilize a low-cost loop heat pipe (LHP) [9-11], a passive cooling device, to dissipate the heat of TEG to increase the net power output. See Fig. 3 for the mechanical design of TEG.

LHP is a heat transfer device widely used in aerospace [9]. LHP consists of an evaporator, a vapor line, a condenser pipe adhered on a heat dissipating surface through a thermal connector, a liquid return line. See Fig. 4. The evaporator is attached on the cold side of the TEG module to absorb the dissipated heat. The absorbed heat evaporates the working fluid inside the LHP which flows through a bendable connecting pipe to the condenser surface. The vapor is condensed and the heat is dissipated to the ambient. The condensed liquid then returns to the evaporator through the connecting pipe by capillary effect of the wick embedded inside the evaporator. Since the pore of the wick is made in micro scale to create a large capillary force, LHP can transport large amount of heat to a long distance. National Taiwan University has developed a new manufacturing process that can make cheap LHP which has been utilized in high-power LED lighting products [10,11].

The thermoelectric generator built in the present study is denoted as "SYS-1", which basically comprises a TEG module and two LHP. A $40 \mathrm{~mm} \times 40 \mathrm{~mm}$ TEG module (Model STE, manufactured by TEG Power Inc.) with $100 \mathrm{~W}$ rated heat input was used. The rated

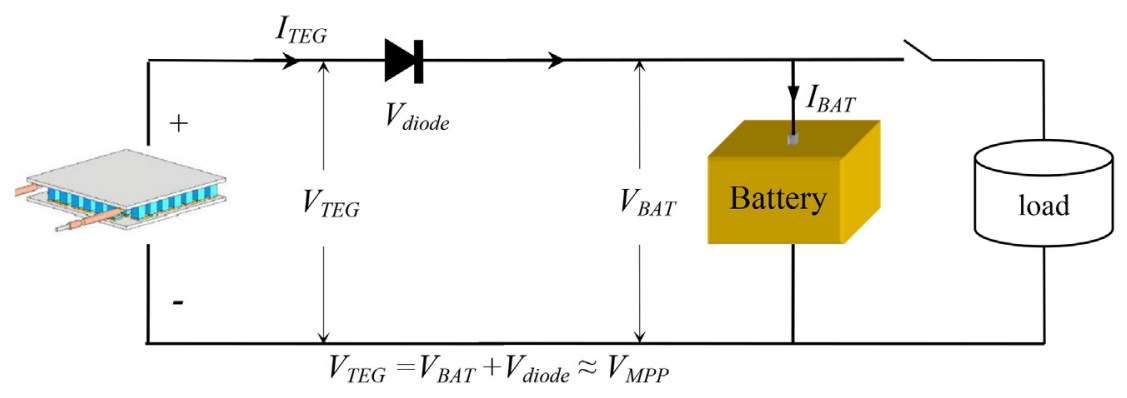

Fig. 2. Schematic diagram of TEG with nMPPO. 

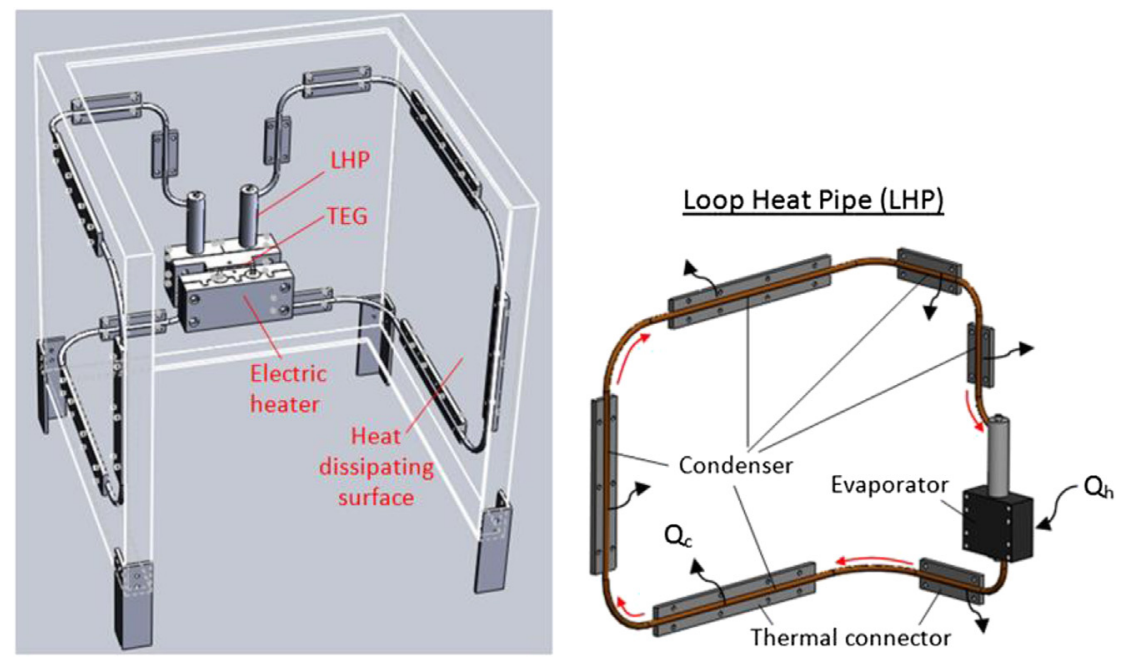

Fig. 3. TEG design using LHP.

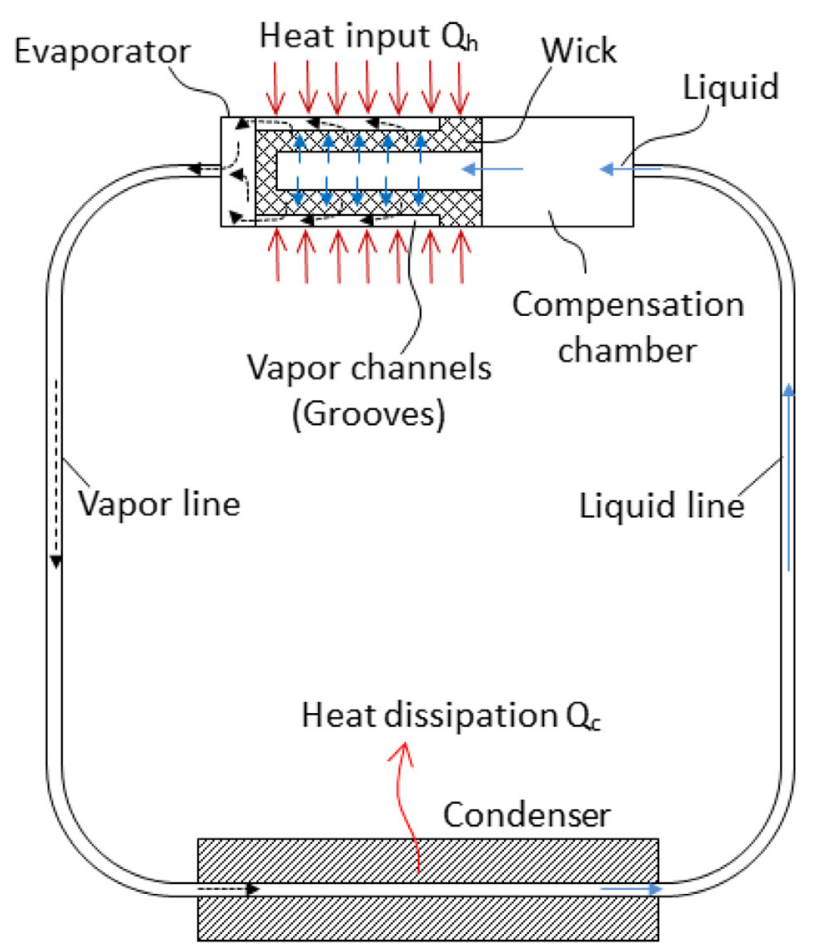

Fig. 4. Schematic of loop heat pipe (LHP).

TEG output power is $3.84 \mathrm{~W}$ at $3.2 \mathrm{~V}$ and at $T_{h}=175{ }^{\circ} \mathrm{C}$ and $T_{c}=30^{\circ} \mathrm{C}$. A cartridge-type electric heater was used to heat the TEG module. Two loop heat pipes were installed to dissipate heat in three vertical surfaces with $30 \mathrm{~cm} \times 30 \mathrm{~cm}$ each, as shown in Fig. 5 . SYS- 1 acts as a basic unit which can be duplicated and connected to form different TEG.

\subsection{Performance test of SYS-1}

The thermoelectric generator SYS- 1 was tested with $T_{c}$ varied. Temperatures at cold and hot sides of TEG module, $T_{c}$ and $T_{h}$, and ambient temperature $T_{a}$ were measured using T-type thermocouples through a Analog Measurement Device ICP-CON 7018Z (10 Channel Thermocouple Input Module) with accuracy $0.5^{\circ} \mathrm{C}$ and 16 -

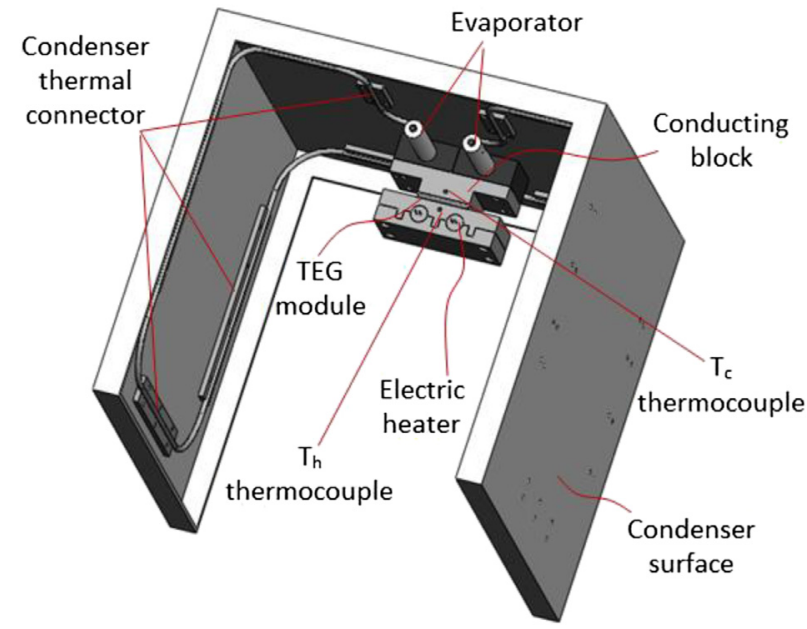

Fig. 5. Design of SYS-1.

bit output. The heat input to TEG is provided by a cartridge heater with DC current input. The cartridge heater is well insulated and the heat input to TEG mdoule $Q_{h}$ is then calculated from measured electrical input power. The input current $I_{h}$ and voltage $V_{h}$ of cartridge heater as well as the output current and voltage of TEG module (ITEG, $V_{T E G}$ ) were measured by a ICP-CON 7017-A5 (High DC Voltage Input Module, 8 Channel) with accuracy $0.5 \%$ and 16 -bit output. Both analog measurement devices were made by msI Measurement Systems Ltd.

It is seen from Table 1 that the best overall energy conversion efficiency of TEG is $3.18 \%$ at temperature difference $147.7{ }^{\circ} \mathrm{C}$ $\left(T_{h}=210.4{ }^{\circ} \mathrm{C}, T_{C}=62.7^{\circ} \mathrm{C}\right)$. The SYS- 1 performance measurement is carried out at various loads (different resistors). Only maximumpower-point performance at each fixed $T_{h}$ and $T_{c}$ is shown in Table 1 . The experimental results show that the LHP performs very well and keeps the cold side temperature $T_{C}$ near $60^{\circ} \mathrm{C}$ at ambient temperature $25{ }^{\circ} \mathrm{C}$. The overall thermal resistance $R_{o}$ from the cold side of TEG module to the ambient decreases with increasing heat transport [9], from 0.43 to $0.35 \mathrm{~K} \mathrm{~W}^{-1}$. $R_{0}$ is defined as

$R_{o}=\frac{T_{h}-T_{c}}{Q_{h}}$ 
Table 1

Test results of SYS- 1 .

\begin{tabular}{|c|c|c|c|c|c|c|c|c|c|}
\hline$T_{h}\left({ }^{\circ} \mathrm{C}\right)$ & $T_{c}\left({ }^{\circ} \mathrm{C}\right)$ & $P_{M P P}(\mathrm{~W})$ & $V_{M P P}(\mathrm{~V})$ & $I_{M P P}(\mathrm{~A})$ & $V_{o c}(\mathrm{~V})$ & $I_{s c}(\mathrm{~A})$ & $Q_{h}(\mathrm{~W})$ & $\eta_{\mathrm{e}}(\%)=P_{M P P} / Q_{h}$ & $R_{o}, \mathrm{~K} \mathrm{~W}^{-1}$ \\
\hline 150.2 & 52.1 & 1.91 & 2.35 & 0.81 & 4.45 & 1.61 & 65.6 & 2.91 & 0.425 \\
\hline 160.6 & 54.3 & 2.12 & 2.47 & 0.86 & 4.77 & 1.68 & 72.4 & 2.93 & 0.417 \\
\hline 170.8 & 56.6 & 2.41 & 2.63 & 0.91 & 5.10 & 1.75 & 78.2 & 3.08 & 0.417 \\
\hline 180.0 & 58.1 & 2.72 & 2.80 & 0.97 & 5.53 & 1.85 & 82.9 & 3.28 & 0.413 \\
\hline 189.8 & 59.5 & 2.98 & 2.88 & 1.03 & 5.74 & 1.94 & 91.4 & 3.26 & 0.390 \\
\hline 200.7 & 61.1 & 3.28 & 3.23 & 1.02 & 6.12 & 2.03 & 105.1 & 3.12 & 0.355 \\
\hline 210.4 & 62.7 & 3.57 & 3.21 & 1.11 & 6.42 & 2.10 & 112.2 & 3.18 & 0.347 \\
\hline
\end{tabular}

The LHP is able to dissipate heat up to $110 \mathrm{~W}$ without power consumption. This is important for small TEG with several watts of power output. Another benefit of using LHP is free of noise in operation of TEG.

\section{Design of TEG with MPPT}

A TEG using MPPT is built for comparison test. Besides, the performance curves of TEG module is measured first for nMPPO design.

\subsection{Measurement of performance curves of TEG module}

The performance curves of TEG module (STE) was first measured using SYS-1 under well-controlled temperatures at the hot and cold sides. $T_{h}$ was automatically regulated by controlling the input power of cartridge electric heater using a PID controller. To obtain a constant cold side temperature $T_{c}$, a fan was used to blow air onto the heat dissipation surface and the fan speed was automatically adjusted to control $T_{c}$.

The $\mathrm{I}-\mathrm{V}$ curve of TEG is determined experimentally from measuring the output current $I_{T E G}$ and voltage $V_{T E G}$ at a given resistance load $R_{0}$. Repeating the measurement at different resistance load $R_{L}$ (load line), the locus of $\mathrm{I}-\mathrm{V}$ as well as $\mathrm{P}-\mathrm{V}$ curve can be drawn as shown in Fig. 6 .

Six power resistors (Table 2) were connected in parallel through a switching device to provide 32 different loads to TEG (Fig. 7). Six relays are connected in series to the power resistors and are turned ON/OFF individually by a microprocessor-based controller (PIC16F877A) through the Parallel Port. The 32 resistance load combinations made from this switching device is shown in Table 3.

The measurement startes when the temperatures at hot and cold sides, $T_{h}$ and $T_{c}$, are kept constant using the temperature

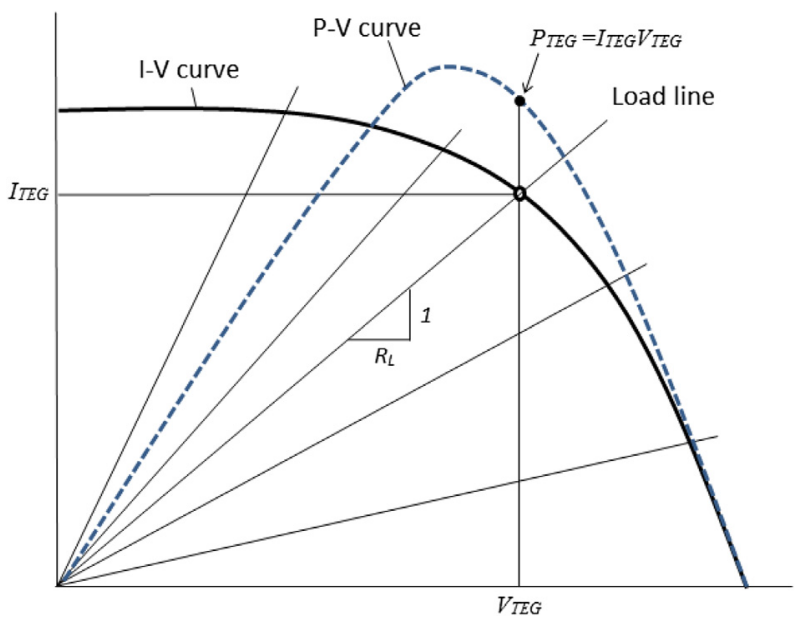

Fig. 6. Measuring procedure of $I-V$ and $P-V$ curves of TEG. control described previously. It takes $14 \mathrm{~s}$ to switch through all the 32 resistor combinations.

Fig. 8 is the measured $\mathrm{P}-\mathrm{V}$ curves, at $T_{c}=50^{\circ} \mathrm{C}$. There exists a maximum power for each operating condition. The locus of maximum-power points (MPP) can be drawn as shown in Fig. 8. The maximum power occurs in the narrow voltage range $V_{T E G}=2.3-3.4 \mathrm{~V}$ for $T_{h}=150-200{ }^{\circ} \mathrm{C}$.

\subsection{Design of MPPT}

In order to compare the performance of TEG using MPPT and nMPPO, a MPPT tracking controller was designed and built. The MPPT is designed using the SEPIC (single-ended primary inductance converter) DC/DC converter [5] controlled by the microprocessor PIC16F877A (Fig. 9). Since the DC/DC circuit has a dynamic effect between input $\left(P_{T E G}\right)$ and output $\left(P_{B A T}\right)$, the MPPT is used to track the maximum power charged to the battery $\left(P_{B A T}\right)$, instead of the maximum power output of TEG $\left(P_{T E G}\right)$. This will assure that the maximum power which is charged to the battery is tracked.

A current sensor is installed at the output of MPPT to measure the battery charging current $I_{B A T}$ and to determine the charging power. The method of perturbation and observation (P.O. method) [7] was used to achieve the maximum-power charging to the battery by increasing or decreasing the PWM duty cycle $(D)$. The feedback system block diagram of MPPT using P.O. method is shown in Fig. 10. The P.O. method is implemented using the onestep delay filter of $P_{B A T}$ and the step-up/step-down controller.

\subsection{Design of TEG with MPPT: TEG-MP1 and TEG-MP2}

A TEG, denoted as "TEG-MP1", was built using a $2.4 \mathrm{~V} / 2.7$ Ah lead-acid battery connected to a unit of SYS-1. The MPPT was installed. The PWM frequency of SEPIC will affect the MPPT performance. $50 \mathrm{kHz}$ was chosen as the PWM frequency $f_{P W M}$.

To reduce the energy loss of diode, another higher voltage TEG, denoted as "TEG-MP2", was designed using a 6 V/10 Ah lead-acid battery which is connected to two units of SYS-1. The two TEG modules are electrically connected in series, but thermally connected in parallel at the same hot side (heat source) and cold side (heat sink).

\subsection{Definition of performance index}

In order to evaluate the performance of TEG with MPPT, three efficiencies $\left(\eta_{T}, \eta_{t k}, \eta_{\text {MPPT }}\right)$ are defined:

(1) Circuit efficiency $\eta_{T}$

Table 2

Power resistors used as TEG load combination.

\begin{tabular}{lllllll}
\hline Resistor & $R_{1}$ & $R_{2}$ & $R_{3}$ & $R_{4}$ & $R_{5}$ & $R_{6}$ \\
\hline Resistance, ohm & 0 & 1.5 & 3.3 & 8 & 15 & 33 \\
\hline
\end{tabular}




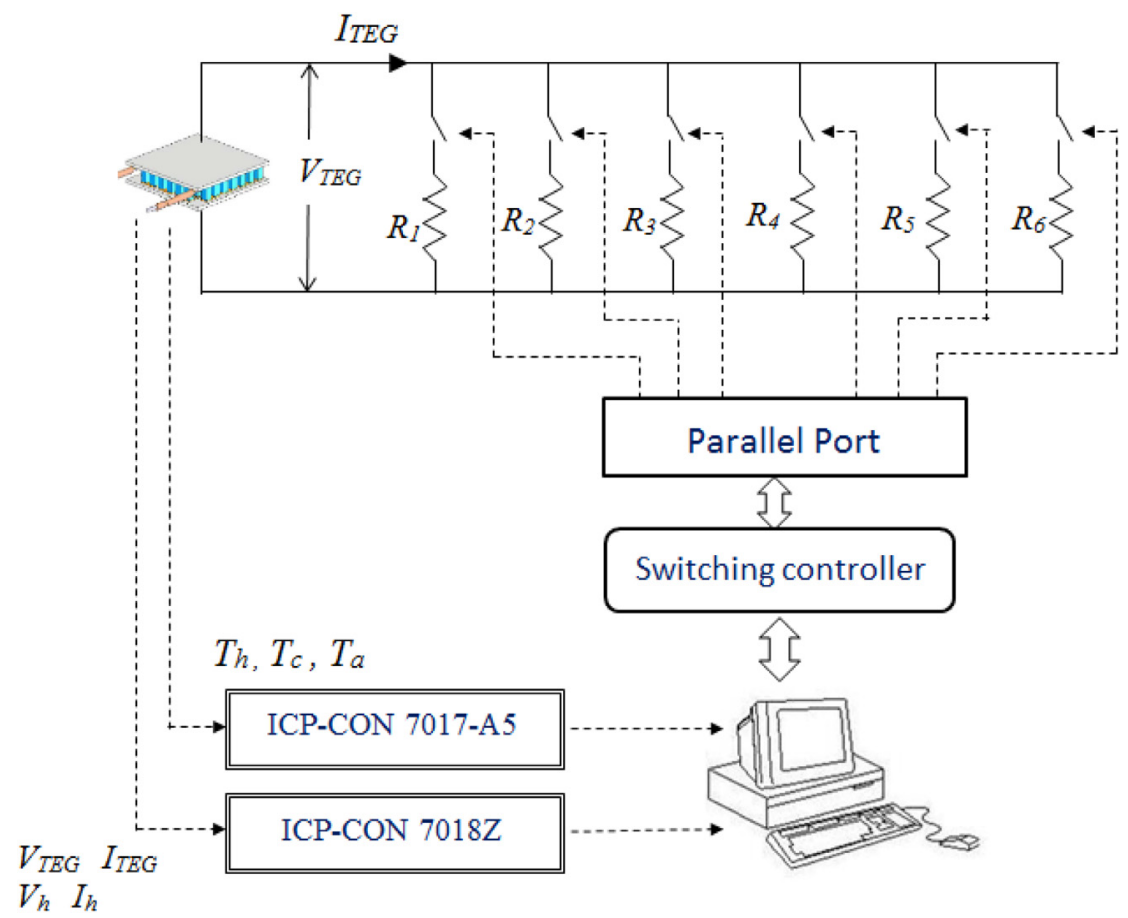

Fig. 7. Switching device for I-V curve measurement.

Table 3

32 different load combinations.

\begin{tabular}{|c|c|c|c|c|c|}
\hline Resistor combination R123456 & Output of parallel port & Equivalent load $R_{L}(\Omega)$ & Resistor combination R123456 & Output of parallel port & Equivalent load $R_{L}(\Omega)$ \\
\hline 000000 & 0 & $\infty$ (O.C.) & 010001 & 17 & 1.43 \\
\hline 000001 & 1 & 33.00 & 010010 & 18 & 1.36 \\
\hline 000010 & 2 & 15.00 & 010011 & 19 & 1.31 \\
\hline 000011 & 3 & 10.31 & 010100 & 20 & 1.26 \\
\hline 000100 & 4 & 8.00 & 010101 & 21 & 1.22 \\
\hline 000101 & 5 & 6.44 & 010110 & 22 & 1.17 \\
\hline 000110 & 6 & 5.22 & 010111 & 23 & 1.13 \\
\hline 000111 & 7 & 4.51 & 011000 & 24 & 1.03 \\
\hline 001000 & 8 & 3.30 & 011001 & 25 & 1.00 \\
\hline 001001 & 9 & 3.00 & 011010 & 26 & 0.96 \\
\hline 001010 & 10 & 2.70 & 011011 & 27 & 0.94 \\
\hline 001011 & 11 & 2.50 & 011100 & 28 & 0.91 \\
\hline 001100 & 12 & 2.34 & 011101 & 29 & 0.89 \\
\hline 001101 & 13 & 2.18 & 011110 & 30 & 0.86 \\
\hline 001110 & 14 & 2.02 & 011111 & 31 & 0.84 \\
\hline 001111 & 15 & 1.90 & 100000 & 32 & 0 (S.C.) \\
\hline 010000 & 16 & 1.50 & & & \\
\hline
\end{tabular}

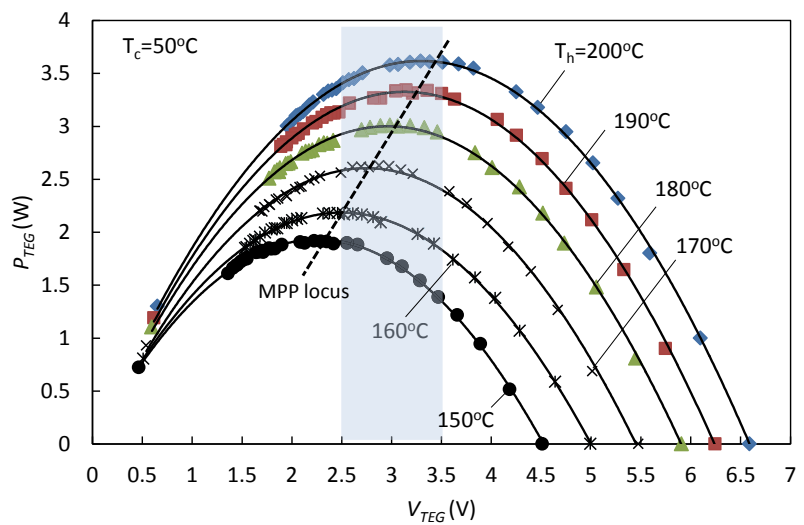

Fig. 8. P-V curves of TEG module (STE).
$\eta_{T}=\frac{P_{B A T}}{P_{T E G}}$

where $P_{T E G}$ is the output power of the TEG module; $P_{B A T}$ is the power charged to the battery. $\eta_{T}$ represents the efficiency of MPPT circuits.

(2) MPP tracking efficiency $\eta_{t k}$

$\eta_{t k}=\frac{P_{T E G}}{P_{M P P}}$

where $P_{M P P}$ is the output power of the TEG module at the MPP. $\eta_{t k}$ represents the tracking efficiency of the MPPT with respect to the MPP of the TEG. 


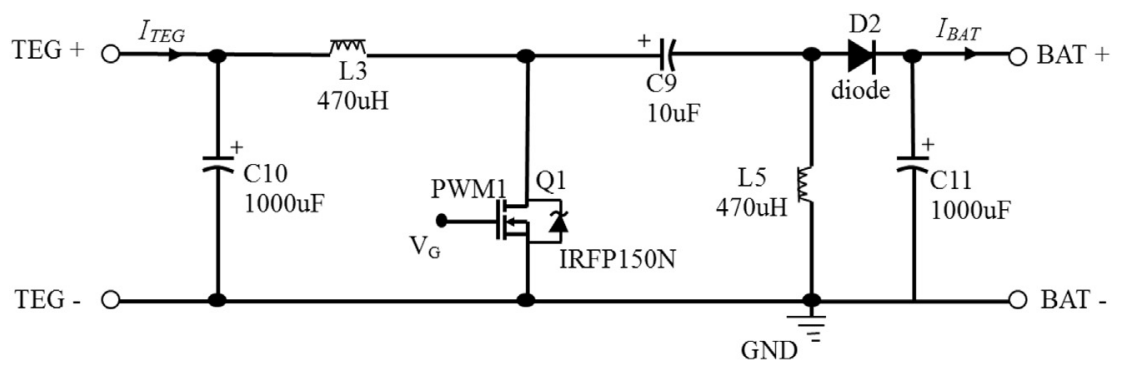

Fig. 9. SEPIC (single-ended primary inductance converter) circuit in MPPT [5].

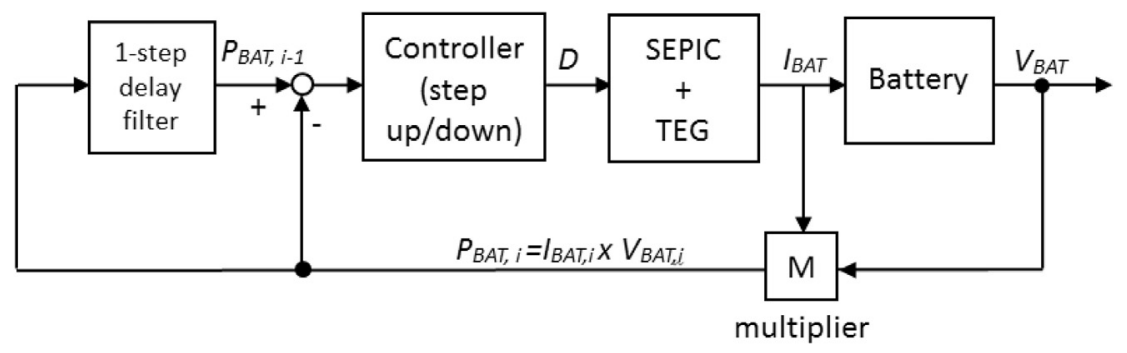

Fig. 10. Feedback control of MPPT using P.O. method.

(3) Overall MPPT tracking efficiency $\eta_{M P P T}$

$\eta_{M P P T}=\frac{P_{B A T}}{P_{M P P}}=\eta_{T} \cdot \eta_{t k}$

$\eta_{M P P T}$ represents the overall tracking efficiency of MPPT from the theoretical maximum power $P_{M P P}$ to the actual power charged to the battery $P_{B A T}$.

\subsection{Test of TEG-MP1}

TEG-MP1 was tested at $T_{h}=210{ }^{\circ} \mathrm{C}$ and $f_{P W M}=50 \mathrm{kHz}$. Fig. 11 and Table 4 show that the maximum power output of TEG occurs at duty cycle $D=60 \%$ which is slightly different from the maximum power actually charged to the battery at duty cycle $D=55 \%$. This is due to the input/output response of the MPPT circuit. If MPPT is applied to the TEG output power $P_{\text {TEG }}$, duty cycle $D$ should be chosen as $D=60 \%$ so that the maximum output $3.65 \mathrm{~W}$ is obtained. The actual power charged to the battery $P_{B A T}$ at $D=60 \%$ will be $2.16 \mathrm{~W}$ which is not the maximum $(2.25 \mathrm{~W})$. This suggests that the maximum power tracking should be applied at the battery charge port $P_{B A T}$, not at the output port of TEG module. If so, about $4 \%$ more output power charged to the battery can be obtained, an increase from $2.16 \mathrm{~W}$ at $D=60 \%$ to $2.25 \mathrm{~W}$ at $D=55 \%$.

Table 4 shows that the MPPT has tracked the maximum-power point (MPP) at $D=60 \%$. However, the overall MPPT tracking efficiency $\eta_{M P P T}$ is low, about $60 \%$. This is due to the low circuit efficiency $\eta_{T}$ resulted mainly from the energy loss of the diode (D2) in the SEPIC circuit (Fig. 9). The diode has a voltage drop $0.5 \mathrm{~V}$ which results in about $18 \%$ energy loss for $2.8 \mathrm{~V}$ battery. PWM1 is a MOSFET switching device which also loss energy.

\subsection{Test of TEG-MP2}

The energy loss of diode in TEG-MP1 is relatively high for low battery voltage. TEG-MP2 comprises a $6 \mathrm{~V} / 10$ Ah battery and two units of SYS-1 electrically connected in series. The two TEG modules

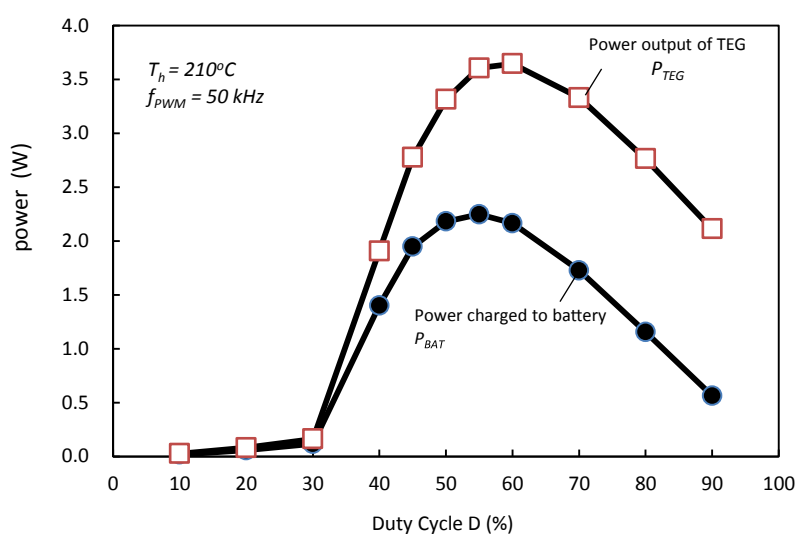

Fig. 11. Variation of TEG module output $\left(P_{T E G}\right)$ and battery charging power $\left(P_{B A T}\right)$ with duty cycle.

are thermally connected in parallel, with the same heat source and heat sink. It is seen from Table 5 that the circuit efficiency $\eta_{T}$ reaches about $80 \%$ in which the diode energy loss is around $8 \%$ and the SEPIC circuit loss is about $12 \%$ at battery voltage $6 \mathrm{~V}$. The MPPT has tracked the maximum-power point (MPP) of the TEG module. The overall MPPT tracking efficiency $\eta_{\text {MPPT }}$ is around $80 \%$ over different $T_{h}$. The test results show that TEG-MP2 performs satisfactory for battery at higher voltage. The major loss comes from the diode (D2) and the circuit of SEPIC.

\section{Design of TEG with nMPPO}

\subsection{TEG design using $n M P P O$}

The design concept of "near maximum-power point operation, nMPPO" is illustrated in Fig. 8. The nMPPO design is simply a system design which properly matches the output voltage of TEG module close to the battery (Fig. 8). There is only one electronic component, a diode, in the circuit between the TEG and the battery for protection purpose. 
Table 4

Performance of TEG-MP1 $\left(f_{p w m}=50 \mathrm{kHz}, T_{h}=210^{\circ} \mathrm{C}\right)$.

\begin{tabular}{|c|c|c|c|c|c|c|c|c|c|c|}
\hline Duty cycle $D(\%)$ & $V_{T E G}(\mathrm{~V})$ & $I_{T E G}(\mathrm{~A})$ & $V_{B A T}(\mathrm{~V})$ & $I_{B A T}(\mathrm{~A})$ & $P_{T E G}(\mathrm{~W})$ & $P_{B A T}(\mathrm{~W})$ & $\begin{array}{l}P_{M P P} \\
(\mathrm{~W})\end{array}$ & $\eta_{T}(\%)=P_{B A T} / P_{T E G}$ & $\eta_{t k}(\%)=P_{T E G} / P_{M P P}$ & $\eta_{M P P T}(\%)=P_{B A T} / P_{M P P}$ \\
\hline 10 & 6.54 & 0.00 & 2.72 & 0.01 & 0.03 & 0.02 & 4.17 & 66.3 & 0.7 & 0.5 \\
\hline 20 & 6.55 & 0.01 & 2.71 & 0.02 & 0.08 & 0.06 & 3.59 & 70.6 & 2.2 & 1.6 \\
\hline 30 & 6.52 & 0.02 & 2.72 & 0.04 & 0.16 & 0.12 & 3.61 & 72.4 & 4.4 & 3.2 \\
\hline 40 & 5.47 & 0.35 & 2.77 & 0.51 & 1.91 & 1.40 & 3.65 & 73.4 & 52.3 & 38.4 \\
\hline 45 & 4.77 & 0.58 & 2.80 & 0.69 & 2.78 & 1.95 & 3.65 & 70.1 & 76.2 & 53.4 \\
\hline 50 & 4.18 & 0.79 & 2.81 & 0.78 & 3.31 & 2.18 & 3.64 & 65.8 & 90.9 & 59.8 \\
\hline 55 & 3.61 & 1.00 & 2.81 & 0.80 & 3.61 & 2.25 & 3.65 & 62.6 & 98.9 & 61.9 \\
\hline 60 & 3.11 & 1.17 & 2.81 & 0.77 & 3.65 & 2.16 & 3.65 & 59.3 & 100.0 & 59.3 \\
\hline 70 & 2.28 & 1.46 & 2.79 & 0.62 & 3.33 & 1.73 & 3.65 & 51.9 & 91.3 & 47.4 \\
\hline 80 & 1.64 & 1.69 & 2.77 & 0.42 & 2.76 & 1.16 & 3.64 & 41.9 & 75.8 & 31.7 \\
\hline 90 & 1.13 & 1.86 & 2.74 & 0.21 & 2.11 & 0.56 & 3.64 & 26.7 & 57.9 & 15.4 \\
\hline
\end{tabular}

Table 5

Performance of TEG-MP2 $\left(f_{p w m}=50 \mathrm{kHz}\right)$.

\begin{tabular}{|c|c|c|c|c|c|c|c|c|c|c|c|c|}
\hline$T_{h}\left({ }^{\circ} \mathrm{C}\right)$ & $T_{c}\left({ }^{\circ} \mathrm{C}\right)$ & Duty cycle $D(\%)$ & $V_{T E G}(\mathrm{~V})$ & $I_{T E G}(\mathrm{~A})$ & $V_{B A T}(\mathrm{~V})$ & $I_{B A T}(\mathrm{~A})$ & $P_{T E G}(\mathrm{~W})$ & $P_{B A T}(\mathrm{~W})$ & $P_{M P P}(\mathrm{~W})$ & $\eta_{T}(\%)=P_{B A T} / P_{T E G}$ & $\eta_{t k}(\%)=P_{T E G} / P_{M P P}$ & $\eta_{M P P T}(\%)=P_{B A T} / P_{M P P}$ \\
\hline 160 & 52 & 57.8 & 5.27 & 0.82 & 5.94 & 0.59 & 4.32 & 3.47 & 4.36 & 80.3 & 99.2 & 79.7 \\
\hline 170 & 55 & 56.9 & 5.59 & 0.87 & 6.00 & 0.64 & 4.87 & 3.86 & 4.92 & 79.3 & 98.9 & 78.5 \\
\hline 180 & 57 & 55.9 & 5.87 & 0.90 & 6.05 & 0.69 & 5.28 & 4.19 & 5.28 & 79.3 & 100.0 & 79.3 \\
\hline 190 & 59 & 54.7 & 6.10 & 0.91 & 6.07 & 0.73 & 5.55 & 4.44 & 5.61 & 80.0 & 99.0 & 79.2 \\
\hline 200 & 61 & 53.8 & 6.31 & 0.93 & 6.08 & 0.78 & 5.87 & 4.72 & 5.90 & 80.4 & 99.5 & 80.0 \\
\hline 210 & 63 & 53.8 & 6.51 & 0.96 & 6.13 & 0.82 & 6.25 & 5.01 & 6.32 & 80.2 & 98.9 & 79.3 \\
\hline
\end{tabular}

By careful matching the specifications of TEG module and battery, we can achieve an nMPPO design which will perform close to that of MPPT.

\subsubsection{Design of nTEG-1}

SYS-1 built for the experiments of MPPT includes a TEG module (Model STE) with rated output power $3.84 \mathrm{~W}$ at $V_{\text {TEG }}=3.2 \mathrm{~V}$ and $T_{h}=175^{\circ} \mathrm{C}$. The voltage of a $2.4 \mathrm{~V} / 2.7 \mathrm{Ah}$ lead-acid battery varies between $2.1 \mathrm{~V}$ and $3 \mathrm{~V}$. Hence, combining a single unit of SYS-1 with a $2.4 \mathrm{~V}$ lead-acid battery will form a design of nMPPO, denoted as "nTEG-1".

nTEG-1 includes a $2.4 \mathrm{~V}$ lead-acid battery which operates at the range $2.1 \sim 3 \mathrm{~V}$. The diode voltage loss $V_{\text {diode }}$ is $0.5 \mathrm{~V}$. Therefore, the resultant voltage across the TEG module is $V_{T E G}=V_{B A T}+V_{\text {diode }}=2.6-3.5 \mathrm{~V}$ which matches the MPP range of TEG module (2.3-3.4 V, Fig. 4).

The mismatch of nMPPO with the MPPT will result in energy generation loss. This mismatch loss is acceptable if it is less than the energy loss of MPPT circuit, usually $10-20 \%$ for small TEG.

Using the $\mathrm{P}-\mathrm{V}$ performance curve of TEG module shown in Fig. 8 , we can calculate the voltage of TEG at $95 \%$ and $90 \%$ (or $5 \%$ and $10 \%$ loss) of the maximum power $P_{M P P}$ at different $T_{h}$ and $T_{c}$, denoted as $V_{M P P 95}$ and $V_{M P P 90}$. Table 6 shows the voltage range of a single TEG module, $V_{M P P 95}$ and $V_{M P P 90}$ at different $T_{h}$ (ranging from 1.75 to $4 \mathrm{~V}$ ). The shaded area in Fig. 8 represents the TEG operating voltage $V_{T E G}=V_{B A T}+V_{\text {diode }}(=2.6-3.5 \mathrm{~V})$ after taking into account the diode voltage drop. For TEG operating at the voltage range of

Table 6

Voltage of nTEG-1 at $95 \%$ and $90 \%$ of maximum power at $T_{C}=50{ }^{\circ} \mathrm{C}$.

\begin{tabular}{lllll}
\hline$T_{h}\left({ }^{\circ} \mathrm{C}\right)$ & $P_{M P P}(\mathrm{~W})$ & $V_{M P P}(\mathrm{~V})$ & $V_{M P P 95}(\mathrm{~V})$ & $V_{M P P 90}(\mathrm{~V})$ \\
\hline 150 & 1.91 & 2.25 & $1.75-2.75$ & $1.54-2.96$ \\
160 & 2.15 & 2.41 & $1.87-2.95$ & $1.65-3.17$ \\
170 & 2.39 & 2.56 & $1.99-3.13$ & $1.75-3.36$ \\
180 & 2.62 & 2.72 & $2.12-3.32$ & $1.87-3.57$ \\
190 & 2.81 & 2.82 & $2.19-3.44$ & $1.94-3.70$ \\
200 & 3.01 & 2.94 & $2.28-3.59$ & $2.01-3.86$ \\
210 & 3.19 & 3.04 & $2.36-3.72$ & $2.08-4.00$ \\
\hline
\end{tabular}

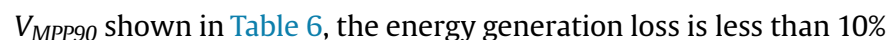
for $T_{h}=180-210{ }^{\circ} \mathrm{C}$ since $V_{M P P 90}$ covers the TEG operating voltage $V_{\text {TEG }}=V_{\text {BAT }}+V_{\text {diode }}(=2.6-3.5 \mathrm{~V})$. For $T_{h}<180{ }^{\circ} \mathrm{C}$, the energy generation loss can be less than $10 \%$ if the TEG operates at a low operating voltage, near $2.6 \mathrm{~V}$. This can be achieved from carefully designing the battery storage. Similarly, as seen from the range of $V_{M P P 95}$, the energy generation loss less than $5 \%$ can be obtained for all $T_{h}$, if the TEG operates at a low operating voltage, near $2.6 \mathrm{~V}$.

\subsubsection{Design of $n T E G-2$}

The circuit efficiency $\eta_{\text {diode }}$ can be increased relatively by increasing the battery voltage. Hence, we designed another higher voltage TEG, denoted "nTEG-2", using two units of SYS-1 connected with a $6 \mathrm{~V} / 10$ Ah lead-acid battery. The two TEG modules are electrically connected in series. The measured $\mathrm{P}-\mathrm{V}$ performance curves of two TEG modules in series are shown in Fig. 12. The cold side temperature $T_{c}$ was not fixed during the tests but varies with the heat dissipation load. The TEG voltage at MPP is in the range 5.0-6.4 V for $T_{h}=150-210^{\circ} \mathrm{C}$.

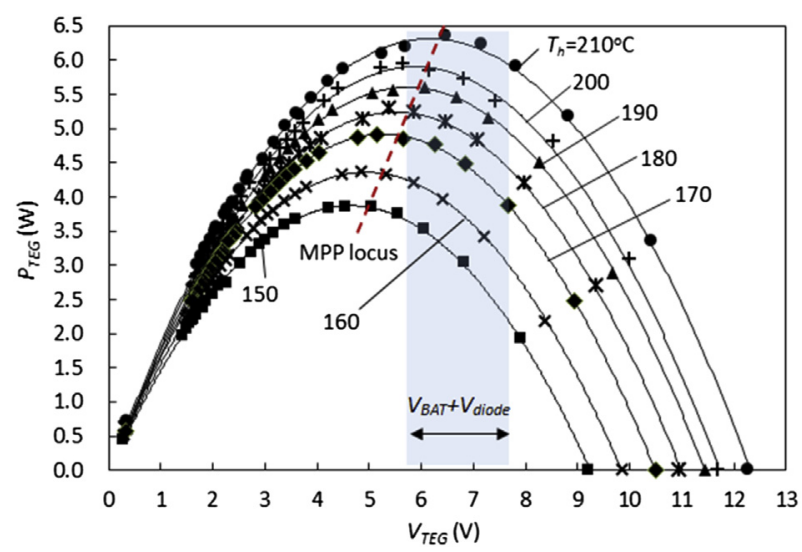

Fig. 12. Measurement of two TEG modules in series (nTEG-2). 
Table 7

Voltage of nTEG-2 at $95 \%, 90 \%$ and $85 \%$ of maximum power.

\begin{tabular}{lllllll}
\hline$T_{h}\left({ }^{\circ} \mathrm{C}\right)$ & $T_{c}\left({ }^{\circ} \mathrm{C}\right)$ & $P_{M P P}(\mathrm{~W})$ & $V_{M P P}(\mathrm{~V})$ & $V_{M P P 95}(\mathrm{~V})$ & $V_{M P 900}(\mathrm{~V})$ & $V_{M P P 85}(\mathrm{~V})$ \\
\hline 150 & 51 & 3.87 & 4.64 & $3.61-5.67$ & $3.18-6.09$ & $2.85-6.42$ \\
160 & 52.7 & 4.33 & 4.88 & $3.80-5.96$ & $3.35-6.41$ & $3.01-6.75$ \\
170 & 54.4 & 4.82 & 5.21 & $4.05-6.36$ & $3.57-6.84$ & $3.20-7.21$ \\
180 & 56.5 & 5.24 & 5.52 & $4.30-6.75$ & $3.79-7.26$ & $3.40-7.65$ \\
190 & 58.6 & 5.75 & 5.78 & $4.50-7.07$ & $3.96-7.60$ & $3.55-8.01$ \\
200 & 60.2 & 6.23 & 6.04 & $4.70-7.39$ & $4.14-7.94$ & $3.71-8.37$ \\
210 & 62.3 & 6.59 & 6.27 & $4.88-7.66$ & $4.30-8.24$ & $3.86-8.68$ \\
\hline
\end{tabular}

The operating voltage of the $6 \mathrm{~V}$ lead-acid battery is between $5.3 \mathrm{~V}$ and $7.2 \mathrm{~V}$. The diode voltage loss $V_{\text {diode }}$ is $0.5 \mathrm{~V}$. Therefore, the resultant voltage across TEG is $V_{T E G}\left(=V_{B A T}+V_{\text {diode }}\right)=5.8-7.7 \mathrm{~V}$ which covers the MPP range of the TEG (5.0-6.4 V).

Using the measured $\mathrm{P}-\mathrm{V}$ performance curve in Fig. 12, we can calculate the voltage range of nTEG- 2 at $95 \%, 90 \%$ and $85 \%$ (or $5 \%$, $10 \%$, and $15 \%$ energy generation loss) of the maximum power $P_{M P P}$ at different $T_{h}$ and $T_{c}$, denoted as $V_{M P P 95}, V_{M P P 90}$, and $V_{M P P 85}$.

The shaded area in Fig. 12 represents the TEG operating voltage $V_{T E G}=V_{B A T}+V_{\text {diode }}(=5.8-7.7 \mathrm{~V})$ after taking into account the diode voltage drop. For TEG operating at the voltage range of $V_{M P P 90}$ shown in Table 7, the energy generation loss is less than $10 \%$ for $T_{h}=200-210{ }^{\circ} \mathrm{C}$ since $V_{M P P 90}$ covers the TEG operating voltage $V_{\text {TEG }}=V_{B A T}+V_{\text {diode }}(=5.8-7.7 \mathrm{~V})$. For $T_{h}<200{ }^{\circ} \mathrm{C}$, the energy generation loss can be less than $10 \%$ if the TEG operates at a lower operating voltage, near $6.0 \mathrm{~V}$. This can be achieved from carefully designing the battery storage. Similarly, as seen from the range of $V_{M P P 95}$, the energy generation loss less than $5 \%$ can be obtained for all $T_{h}$, if the TEG operates at a lower operating voltage, near $5.8 \mathrm{~V}$. The above estimated energy generation loss by using nMPPO design is a conservative result.

\subsection{Performance index for TEG design using $n M P P O$}

In order to experimentally evaluate the performance of TEG with nMPPO design, three efficiencies $\left(\eta_{\text {diode }}, \eta_{\text {otk }}, \eta_{\text {nMPPO }}\right)$ are defined:

(1) Circuit efficiency $\eta_{o T}$

$\eta_{o T}=\eta_{\text {diode }}=\frac{P_{B A T}}{P_{T E G}}$

Where $P_{T E G}$ is the power output of the TEG module; $P_{B A T}$ is the power charged to the battery. $\eta_{\text {diode }}$ is the efficiency of the circuit in nMPPO which has only a component, diode.

(2) MPP tracking efficiency $\eta_{\text {otk }}$

$\eta_{\text {otk }}=\frac{P_{T E G}}{P_{M P P}}$

Where $P_{M P P}$ is the power output of TEG module at MPP (maximumpower point). $\eta_{\text {otk }}$ is the tracking efficiency of the nMPPO design with respect to the MPP of the TEG.

(3) Overall nMPPO tracking efficiency $\eta_{n M P P O}$

$\eta_{n M P P O}=\frac{P_{B A T}}{P_{M P P}}=\eta_{\text {diode }} \cdot \eta_{\text {otk }}$ $\eta_{n M P P O}$ is the overall tracking efficiency of the nMPPO design from the maximum power output of TEG, $P_{M P P}$, to the actual power charged to the battery $P_{B A T}$.

\subsection{Test of nTEG-1}

The performance of nTEG-1 is measured and compared to TEG with MPPT. The test is thus conducted at different battery voltages to evaluate the performance of nTEG-1.

The performance test results of nTEG- 1 with $2.4 \mathrm{~V} / 2.7$ Ah battery are shown in Table 8 . The cold side temperature $T_{c}$ was not fixed during the tests but varies with the heat load. This reflects the actual operation of a TEG. For battery voltage $V_{B A T}$ between $2.49 \mathrm{~V}$ and $2.54 \mathrm{~V}$, the MPP tracking efficiency $\eta_{o t k}$ of nTEG-1 is larger than $96 \%$ at $T_{h}>170^{\circ} \mathrm{C}$. This means that the design of nMPPO causes only about $4 \%$ energy loss of the maximum power generation. The measured circuit efficiency $\eta_{\text {diode }}$ is around $85 \%$ or the energy loss of the diode about $15 \%$. The overall nMPPO tracking efficiency $\eta_{n M P P O}$ is between $78 \%$ and $84 \%$ which is larger than that of TEG-MP1 ( $\eta_{\text {MPPT }}$ around $62 \%$ as shown in Table 4 ).

For battery voltage at 3.00-3.10 V, the MPP tracking efficiency $\eta_{\text {otk }}$ is larger than $90 \%$ at $T_{h}>170^{\circ} \mathrm{C}$. The measured circuit efficiency $\eta_{\text {diode }}$ is around $87 \%$. The overall nMPPO tracking efficiency $\eta_{n M P P O}$ is between $65 \%$ and $82 \%$ which is larger than that of TEG-MP1 $\left(\eta_{\text {MPPT }}\right.$ around $62 \%$ due to large energy loss in circuits as shown in Table 4). The diode voltage drop is $0.5 \mathrm{~V}$. $\eta_{n M P P O}$ can be further improved if the diode is changed using a better one.

\subsection{Test of $n T E G-2$}

The performance test results of nTEG- 2 with $6 \mathrm{~V} / 10$ Ah battery are shown in Table 9. It is seen that the MPP tracking efficiency $\eta_{\text {otk }}$ is larger than $96 \%$ at $T_{h}>170{ }^{\circ} \mathrm{C}$ for low battery voltage around $5.8 \mathrm{~V}$. The design of nMPPO causes only about $4 \%$ energy loss of the maximum-power generation. The measured circuit efficiency $\eta_{\text {diode }}$ is around $91 \%$. The overall nMPPO tracking efficiency $\eta_{n M P P O}$ of nTEG- 2 is around $89 \%$ which is larger than that of TEG-MP2 $\left(\eta_{M P P T}\right.$ around $80 \%$ shown in Table 5 ).

For TEG operating at high battery voltage around $7.1 \pm 0.5 \mathrm{~V}$, the MPP tracking efficiency $\eta_{o t k}$ is reduced and the overall nMPPO tracking efficiency $\eta_{n M P P O}$ are about the same as $\eta_{M P P T}$ of TEG-MP2.

The experimental results suggest that the design of nMPPO causes small energy generation loss if the TEG operated at low battery voltage. This can be achieved from carefully designing the battery storage. The diode voltage drop is $0.5 \mathrm{~V}$. $\eta_{n M P P O}$ can be further improved if the diode has a lower voltage drop.

\section{Discussions}

\subsection{Comparison of TEG design using MPPT and nMPPO}

The TEG module (STE) used in the present study is designed to work at $T_{h}<210^{\circ} \mathrm{C}$ with temperature difference around $150{ }^{\circ} \mathrm{C}$, i.e. $T_{C}$ around $60^{\circ} \mathrm{C}$. We can compare the performance of the four TEG systems (TEG-MP1, TEG-MP2, nTEG-1, nTEG-2) and find out the feasibility of the design using nMPPO. Table 10 summarizes the test results at $T_{h}=200$ and $210{ }^{\circ} \mathrm{C}$ for different battery voltages. It is seen that the MPP tracking efficiencies of TEG-MP1 and TEG-MP2, $\eta_{t k}$, are higher than $98.9 \%$. On the other hand, the MPP tracking efficiencies of nTEG-1 and nTEG-2, $\eta_{\text {otk }}$, are also higher than $97.2 \%$ for battery running at lower voltage as shown in the highlights of Table 10 . At higher $V_{B A T}, \eta_{\text {otk }}$ are between $92.1 \%$ and $95 \%$ which is still satisfactory.

$\eta_{\text {MPPT }}$ of TEG-MP1 is the lowest (61.9\%) since it uses a $2.4 \mathrm{~V}$ battery which results in a relatively large energy loss from the 
Table 8

Performance test of nTEG-1.

\begin{tabular}{|c|c|c|c|c|c|c|c|c|c|c|}
\hline$T_{h}\left({ }^{\circ} \mathrm{C}\right)$ & $P_{M P P}(\mathrm{~W})$ & $V_{T E G}(\mathrm{~V})$ & $I_{T E G}(\mathrm{~A})$ & $V_{B A T}(\mathrm{~V})$ & $I_{B A T}(\mathrm{~A})$ & $P_{T E G}(\mathrm{~W})$ & $P_{B A T}(\mathrm{~W})$ & $\eta_{\text {otk }}(\%)=P_{T E G} / P_{\mathrm{MPP}}$ & $\eta_{\text {diode }}(\%)=P_{B A T} / P_{\mathrm{TEG}}$ & $\eta_{n M P P O}(\%)=P_{B A T} / P_{M P P}$ \\
\hline 150 & 1.91 & 2.82 & 0.62 & 2.41 & 0.62 & 1.75 & 1.50 & 91.6 & 85.5 & 78.3 \\
\hline 160 & 2.11 & 2.90 & 0.69 & 2.47 & 0.69 & 2.01 & 1.71 & 94.9 & 85.3 & 80.9 \\
\hline 170 & 2.41 & 2.93 & 0.79 & 2.49 & 0.79 & 2.31 & 1.96 & 96.1 & 84.8 & 81.5 \\
\hline 180 & 2.72 & 2.97 & 0.88 & 2.51 & 0.88 & 2.63 & 2.22 & 96.5 & 84.4 & 81.4 \\
\hline 190 & 2.98 & 3.00 & 0.99 & 2.52 & 0.99 & 2.97 & 2.50 & 99.7 & 84.0 & 83.7 \\
\hline 200 & 3.28 & 3.03 & 1.08 & 2.54 & 1.08 & 3.28 & 2.75 & 99.8 & 83.8 & 83.6 \\
\hline 150 & 1.91 & 3.42 & 0.41 & 3.00 & 0.41 & 1.41 & 1.25 & 73.8 & 88.6 & 65.3 \\
\hline 160 & 2.11 & 3.42 & 0.51 & 3.02 & 0.51 & 1.74 & 1.54 & 82.3 & 88.1 & 72.7 \\
\hline 170 & 2.41 & 3.45 & 0.60 & 3.03 & 0.60 & 2.07 & 1.81 & 86.0 & 87.5 & 75.2 \\
\hline 180 & 2.72 & 3.52 & 0.70 & 3.07 & 0.70 & 2.46 & 2.15 & 90.4 & 87.2 & 78.9 \\
\hline 190 & 2.98 & 3.56 & 0.78 & 3.09 & 0.78 & 2.78 & 2.42 & 93.1 & 86.9 & 81.0 \\
\hline 200 & 3.28 & 3.58 & 0.87 & 3.10 & 0.87 & 3.12 & 2.71 & 95.0 & 86.7 & 82.4 \\
\hline
\end{tabular}

Table 9

Performance test of nTEG-2.

\begin{tabular}{|c|c|c|c|c|c|c|c|c|c|c|c|}
\hline$T_{h}\left({ }^{\circ} \mathrm{C}\right)$ & $T_{c}\left({ }^{\circ} \mathrm{C}\right)$ & $P_{M P P}(\mathrm{~W})$ & $V_{T E G}(\mathrm{~V})$ & $I_{T E G}(\mathrm{~A})$ & $V_{B A T}(\mathrm{~V})$ & $I_{B A T}(\mathrm{~A})$ & $P_{\text {TEG }}(\mathrm{W})$ & $P_{B A T}(\mathrm{~W})$ & $\eta_{o t k}(\%)=P_{T E G} / P_{M P P}$ & $\eta_{\text {diode }}(\%)=P_{B A T} / P_{T E G}$ & $\eta_{n M P P O}(\%)=P_{B A T} / P_{M P P}$ \\
\hline 160 & 50.5 & 4.36 & 6.27 & 0.63 & 5.80 & 0.63 & 3.95 & 3.66 & 90.6 & 92.5 & 83.9 \\
\hline 170 & 52.7 & 4.92 & 6.33 & 0.73 & 5.83 & 0.73 & 4.63 & 4.27 & 94.1 & 92.2 & 86.7 \\
\hline 180 & 54.7 & 5.24 & 6.38 & 0.79 & 5.85 & 0.79 & 5.06 & 4.65 & 96.6 & 91.8 & 88.7 \\
\hline 190 & 56.7 & 5.61 & 6.42 & 0.85 & 5.87 & 0.85 & 5.44 & 4.97 & 97.0 & 91.4 & 88.7 \\
\hline 200 & 58.7 & 5.90 & 6.46 & 0.89 & 5.89 & 0.89 & 5.74 & 5.24 & 97.2 & 91.3 & 88.7 \\
\hline 210 & 60.6 & 6.32 & 6.49 & 0.95 & 5.91 & 0.95 & 6.19 & 5.64 & 98.1 & 91.1 & 89.3 \\
\hline 160 & 50.6 & 4.36 & 7.06 & 0.49 & 6.63 & 0.49 & 3.43 & 3.22 & 78.6 & 93.9 & 73.8 \\
\hline 170 & 53.0 & 4.91 & 7.32 & 0.55 & 6.87 & 0.55 & 4.02 & 3.78 & 81.8 & 93.9 & 76.8 \\
\hline 180 & 55.1 & 5.24 & 7.56 & 0.59 & 7.11 & 0.59 & 4.52 & 4.20 & 86.3 & 92.8 & 80.1 \\
\hline 190 & 57.1 & 5.60 & 7.85 & 0.62 & 7.38 & 0.62 & 4.96 & 4.58 & 88.6 & 92.2 & 81.7 \\
\hline 200 & 59.5 & 5.90 & 7.96 & 0.65 & 7.47 & 0.65 & 5.44 & 4.85 & 92.1 & 89.3 & 82.2 \\
\hline 210 & 61.4 & 6.31 & 8.11 & 0.69 & 7.62 & 0.69 & 5.91 & 5.23 & 93.6 & 88.5 & 82.9 \\
\hline
\end{tabular}

Table 10

Performance comparison.

\begin{tabular}{|c|c|c|c|c|c|c|c|c|c|c|c|c|}
\hline & $T_{h}\left({ }^{\circ} \mathrm{C}\right)$ & $T_{c}\left({ }^{\circ} \mathrm{C}\right)$ & $V_{T E G}(\mathrm{~V})$ & $I_{T E G}(\mathrm{~A})$ & $V_{B A T}(\mathrm{~V})$ & $I_{B A T}(\mathrm{~A})$ & $P_{T E G}(\mathrm{~W})$ & $P_{B A T}(\mathrm{~W})$ & $P_{M P P}(\mathrm{~W})$ & $\eta_{T}(\%)=P_{B A T} / P_{T E G}$ & $\eta_{t k}(\%)=P_{T E G} / P_{M P P}$ & $\eta_{M P P T}(\%)=P_{B A T} / P_{M P P}$ \\
\hline TEG-MP1 & 210 & 62 & 3.61 & 1.00 & 2.81 & 0.80 & 3.61 & 2.25 & 3.65 & 62.6 & 98.9 & 61.9 \\
\hline TEG-MP2 & 200 & 61 & 6.31 & 0.93 & 6.08 & 0.78 & 5.87 & 4.72 & 5.90 & 80.4 & 99.5 & 80.0 \\
\hline \multirow[t]{2}{*}{ TEG-MP2 } & 210 & 63 & 6.51 & 0.96 & 6.13 & 0.82 & 6.25 & 5.01 & 6.32 & 80.2 & 98.9 & 79.3 \\
\hline & $T_{h}\left({ }^{\circ} \mathrm{C}\right)$ & $T_{c}\left({ }^{\circ} \mathrm{C}\right)$ & $V_{T E G}(\mathrm{~V})$ & $I_{T E G}(\mathrm{~A})$ & $V_{B A T}(\mathrm{~V})$ & $I_{B A T}(\mathrm{~A})$ & $P_{T E G}(\mathrm{~W})$ & $P_{B A T}(\mathrm{~W})$ & $P_{M P P}(\mathrm{~W})$ & $\eta_{\text {diode }}(\%)=P_{B A T} / P_{T E G}$ & $\eta_{o t k}(\%)=P_{T E G} / P_{M P P}$ & $\eta_{n M P P O}(\%)=P_{B A T} / P_{M P P}$ \\
\hline nTEG-1 & 200 & 59 & 3.03 & 1.08 & 2.54 & 1.08 & 3.28 & 2.75 & 3.28 & 83.8 & 99.8 & 83.6 \\
\hline nTEG-1 & 200 & 60 & 3.58 & 0.87 & 3.10 & 0.87 & 3.12 & 2.71 & 3.28 & 86.7 & 95.0 & 82.4 \\
\hline nTEG-2 & 200 & 59 & 6.46 & 0.89 & 5.89 & 0.89 & 5.74 & 5.24 & 5.90 & 91.3 & 97.2 & 88.7 \\
\hline nTEG-2 & 200 & 60 & 7.96 & 0.65 & 7.47 & 0.65 & 5.44 & 4.85 & 5.90 & 89.3 & 92.1 & 82.2 \\
\hline nTEG-2 & 210 & 61 & 6.49 & 0.95 & 5.91 & 0.95 & 6.19 & 5.64 & 6.32 & 91.1 & 98.1 & 89.3 \\
\hline nTEG-2 & 210 & 61 & 8.11 & 0.69 & 7.62 & 0.69 & 5.91 & 5.23 & 6.32 & 88.5 & 93.6 & 82.9 \\
\hline
\end{tabular}

diode voltage drop $(0.5 \mathrm{~V})$. TEG-MP2 uses a $6 \mathrm{~V}$ battery and has a higher $\eta_{\text {MPPT }}$ around $80 \%$. However, the $\eta_{\text {MPPT }}$ of both TEG-MP1 and TEG-MP2 (61.9-80\%) are all less than the $\eta_{n M P P O}$ of nTEG-1 and nTEG-2 (82.2-89.3\%) at different battery voltage. This indicates that the reduction of nMPPO power generation from the MPP is less than the energy loss of the MPPT circuit. The TEG design using nMPPO is more efficient and feasible.

Only two kinds of battery specifications (2.4 V and $6 \mathrm{~V}$ ) were used in the present study. In some applications, the different combination of TEG modules can be used to fit the arbitrary battery specification, for example, $3.6 \mathrm{~V}, 12 \mathrm{~V}$ or $24 \mathrm{~V}$, using the nMPPO design method.

\subsection{Advantages of TEG using loop heat pipe}

The TEGs built in the present study use LHP (loop heat pipe) as the passive cooling device which consumes no power and free of noise. LHP also requires no maintenance since it has no moving parts. The net power output can be kept high. For example, for TEG-
MP1 running at $T_{h}=210^{\circ} \mathrm{C}$, the power output of TEG, $P_{T E G}$, is $3.61 \mathrm{~W}$ (Table 10). The fan power consumption of an active cooling device will be around $2 \mathrm{~W}$ in dissipating about $110 \mathrm{~W}$ heat for TEG-MP1. This will reduce about 55\% of the TEG power output. The use of LHP is thus important for small TEG with several watts of power output, as in some commercial battery charging devices.

The thermal resistance of the present LHP cooling device can be further reduced by using a larger heat dissipating surface or exposing to an environment with natural wind. This will increase the power output of the TEG.

\subsection{Efficiency improvement of MPPT and nMPPO}

The diode used in the SEPIC circuit of MPPT and in the nMPPO circuit causes a voltage drop $(0.5 \mathrm{~V})$ as well as energy loss. The diode loss is relatively large for a low-voltage TEG. This loss can be reduced if using a lower voltage drop diode such as Schottky diode, says, $<0.3 \mathrm{~V}$. Another way to improve the overall efficiency is to 
adopt a higher-voltage battery TEG system, for example, $12 \mathrm{~V}$ or $24 \mathrm{~V}$.

\section{Conclusion}

The conversion efficiency of current thermoelectric generator is low. This means that $96 \mathrm{~W}$ heat should be dissipated for a $4 \mathrm{~W}$ power output of TEG. Conventional heat sink device using fins with fans will consume about $2 \sim 3 \mathrm{~W}$ to dissipate the heat and cause the net power generation of TEG greatly reduced. The present study propose a TEG design using loop heat pipe (LHP), a passive cooling device, to dissipate heat to the ambient by free convection. The heat is transported to a large surface at a distance and dissipated without power consumption and noise. The experiments for a TEG with rated power $4 \mathrm{~W}$ show that the LHP performs very well with thermal resistance $0.35 \mathrm{~K} \mathrm{~W}^{-1}$, from the cold side of TEG module to the ambient.

For TEG, a MPPT (maximum-power point tracking controller) is necessary in order to maximize the power generation. However, it has energy loss in the circuit and reliability problem due to hardware failure. In the present study, we develop a so-called "near maximum-power point operation (nMPPO)" method for the design of TEG to eliminate the MPPT. nMPPO is simply a system design which properly matches the output voltage of TEG at the battery voltage.

Two TEG (nTEG-1 and nTEG2) were designed and built using nMPPO design. The test results were compared with the performance of TEG-MP1 and TEG-MP2.

It is found that the MPP tracking efficiencies of TEG-MP1 and TEG-MP2, $\eta_{t k}$, are higher than $98.9 \%$. The MPP tracking efficiencies of nTEG-1 and nTEG2, $\eta_{o t k}$, are also higher than $97.2 \%$ for battery running at lower voltage $V_{B A T}$. At higher $V_{B A T}, \eta_{\text {otk }}$ are between $92.1 \%$ and $95 \%$ which is still satisfactory.

The $\eta_{\text {MPPT }}$ of both TEG-MP1 and TEG-MP2 (61.9-80\%) are all less than the $\eta_{n M P P O}$ of nTEG-1 and nTEG-2 $(82.2-89.3 \%)$ at different battery voltage. This indicates that the reduction of nMPPO power generation from the value of MPP is less than the energy loss of the MPPT circuit. The TEG design using nMPPO is better.

\section{Acknowledgements}

This publication is based in part on work supported by Award No. KUK-C1-014-12, made by King Abdullah University of Science and Technology (KAUST), Saudi Arabia.

\section{Nomenclature}

$D \quad$ duty cycle of PWM signal in the SEPIC circuit, \%

$I_{B A T} \quad$ current charged to the battery, A

$I_{M P P} \quad$ maximum-power-point current of TEG module, A

$I_{S c} \quad$ short-circuit current of TEG module, A

$I_{\text {TEG }} \quad$ output current of TEG module, A

$Q_{h} \quad$ heat input at hot-side of TEG module, W
$T_{C}$

$T_{h}$

$P_{B A T}$

$P_{T E G}$

$P_{M P P}$

$R_{0}$

\section{$R_{L}$}

$V_{M P P}$

$V_{M P P 95}$

$V_{M P P 90}$

$V_{M P P 85}$

$V_{O C}$

$V_{T E G}$

$\eta_{\text {diode }}$

$\eta_{e}$

$\eta_{M P P T}$

$\eta_{n M P P O}$

$\eta_{\text {otk }}$

$\eta_{T}$

$\eta_{t k}$ maximum-power point at which maximum power is generated from the TEG module cold side temperature of TEG module, ${ }^{\circ} \mathrm{C}$ hot side temperature of TEG module, ${ }^{\circ} \mathrm{C}$ power charged to the battery, $\mathrm{W}$ actual power generated from the TEG module, $\mathrm{W}$ power generated from the TEG module at the MPP, W overall thermal resistance from the cold side of TEG module to the ambient, $\mathrm{K} \mathrm{W}^{-1}$, Eq. (1) equivalent resistance load connected to the TEG, Ohm maximum-power-point voltage of TEG module, $\mathrm{V}$ voltage of TEG at $95 \%$ of the maximum power $P_{M P B}, \mathrm{~V}$ voltage of TEG at $90 \%$ of the maximum power $P_{M P P}, \mathrm{~V}$ voltage of TEG at $85 \%$ of the maximum power $P_{M P P}, \mathrm{~V}$ open-circuit voltage of TEG module, $\mathrm{V}$ output voltage of TEG module, $\mathrm{V}$ efficiency of the circuit of the nMPPO (diode) energy conversion efficiency of TEG $=P_{M P P} / Q_{h}$ overall MPPT tracking efficiency $\left(=P_{B A T} / P_{M P P}=\eta_{T} \eta_{t k}\right)$, Eq. (4)

overall nMPPO tracking efficiency $\left(P_{B A T} / P_{M P P}=\eta_{\text {diode }} \eta_{o t k}\right)$, Eq. (7)

MPP tracking efficiency in nMPPO $\left(=P_{T E G} / P_{M P P}\right)$, Eq. (6) circuit efficiency of MPPT or nMPPO $\left(=P_{B A T} / P_{T E G}\right)$, Eq. $(6)$ or (5) MPP tracking efficiency $\left(=P_{T E G} / P_{M P P}\right)$, Eq. (3)

\section{References}

[1] M.S. El-Genk, H.H. Saber, High efficiency segmented thermoelectric unicouple for operation between 973 and 300K, Energy Convers. Manag. 44 (2003) 1069-1088.

[2] Anders Killander, J.C. Bass, A stove-top generator for cold areas, in: Proc IEEE 15th International Conference on Thermoelectric, 1996, pp. 390-393.

[3] R. Mahmudur, S. Roger, Thermoelectric power-generation for battery charging, in: Proc IEEE Conference on Energy Management and Power Delivery, 1, 1995, pp. 186-191.

[4] W. Roth, Grid-independent power-supply for repeaters in mobile radio networks using photovoltaic/thermoelectric hybrid systems, in: Proc 16th International Conference on Thermoelectric, 1997, pp. 582-585.

[5] J. Eakburanawat, I. Boonyaroonate, Development of a thermoelectric batterycharger with microcontroller-based maximum power point tracking technique, Appl. Energy 83 (2006) 687-704.

[6] Chuang Yu, K.T. Chau, Thermoelectric automotive waste heat energy recovery using maximum power point tracking, Energy Convers. Manag. 50 (2009) 1506-1512.

[7] C. Hua, C. Shen, Study of maximum power tracking techniques and control of $\mathrm{dc} / \mathrm{dc}$ converters for photovoltaic power system, in: Proceedings of 29th Annual IEEE PESC, IEEE Computer Soc. Press, New York, USA, 1998, pp. 86-93.

[8] B.J. Huang, F.S. Sun, R.W. Ho, Near-Maximum-Power-Point-Operation (nMPPO) design of photovoltaic power generation system, Sol. Energy 80 (8) (2006) 1003-1020.

[9] Y. Maydanik, Review loop heat pipes, Appl. Therm. Eng. 25 (5\&6) (2005) 635-657.

[10] B.J. Huang, H.H. Huang, C.W. Chen, M.S. Wu, Development of high-power LED lighting luminaries using loop heat pipe, J. Light Vis. Env 32 (2) (2008) $148-155$.

[11] B.J. Huang, C.H. Wang, T.T. Lin, H.H. Huang, Y.Y. Yeh, Development of a lowcost LHP for commercial application, in: 13th International Heat Pipe Conference (13th IHPC), Shanghai, China, September 21-25, 2004. 